\title{
Sub-clinical systemic lupus erythematosus presenting with acute myocarditis
}

\author{
K. Sandrasegaran, C.W.F. Clarke and V. Nagendran ${ }^{1}$ \\ Department of Medicine, Russells Hall Hospital and ${ }^{1}$ Sub-regional Department of Clinical Immunology, \\ Dudley, West Midlands DY1 2HQ, UK
}

\begin{abstract}
Summary: A 46 year old woman presented with fever and normochromic anaemia followed rapidly by severe myocardial failure, unresponsive to maximum inotropic support and broad spectrum antibiotics. There were no classical clinical stigmata of systemic lupus erythematosus (SLE) but a possible immunological cause was looked for, and on the basis of her immuno-serology a diagnosis of SLE-like disease was made. She responded rapidly to high dose steroids. The importance of considering the possibility of SLE or 'lupus overlap' in an acutely ill 'undiagnosed' patient is emphasized. The relevance of instigating appropriate immuno-serological tests in the course of such an illness is discussed.
\end{abstract}

\section{Introduction}

Pericarditis is the commonest of the many cardiovascular manifestations of systemic lupus erythematosus (SLE) and is readily recognized clinically., In contrast, lupus myocarditis is more difficult to diagnose without resorting to invasive techniques such as endomyocardial biopsy ${ }^{3}$ or investigations such as magnetic resonance imaging, ${ }^{4}$ which are not readily available.

SLE is characterized by the production of antibodies to many nuclear and non-nuclear antigens. Although antibody to double-stranded DNA (dsDNA) is historically the most important, too much reliance should not be placed on its presence in making the clinical diagnosis of SLE. The prevalence of antibodies to ds-DNA in SLE varies according to the method of assay used, and is found to be as low as $70 \%$ when measured by radioimmunoassay. ${ }^{5}$

Anti-Ro (SS-A) and anti-La (SS-B) are antibodies to soluble tissue ribonucleoprotein antigens that have been defined by immunodiffusion techniques. Anti-Ro positivity is reported in a third of patients with SLE. ${ }^{6,7}$ Clinically, anti-Ro is associated with ANA-negative SLE, Sjogren's syndrome, subacute cutaneous lupus erythematosus and neonatal congenital heart block. ${ }^{8}$ Anti-Ro is very rarely positive in normal individuals or hospitalized patients with non-rheumatic disorders ${ }^{9}$ which makes it a useful marker of a connective tissue disease in patients with an atypical presentation.

Correspondence: C.W.F. Clarke, F.R.C.P.(Glas.). Accepted: 29 November 1991
We describe a patient who presented with a near-fatal illness which was characterized by severe myocardial failure. This was associated with ANA positive, ds-DNA negative, Ro antibody positive serology. She responded rapidly to intravenous steroids.

\section{Case report}

In mid-1990 a 42 year old school teacher presented with a seven day history of fever, which failed to respond to chloramphenicol, prescribed prior to her admission.

On examination her temperature was $38.5^{\circ} \mathrm{C}$. She was dyspnoeic, but the chest was clinically and radiologically normal, and there were no overt signs of cardiac failure. No source of bleeding was identified. The electrocardiogram (ECG) showed slight ST depression in the anterolateral leads. There were no manifestations of connective tissue disease or a vasculitic process. In particular, she did not have joint involvement, skin lesions or mucosal dryness.

Results of initial investigations were as follows (reference ranges in brackets): haemoglobin 7.0 $\mathrm{g} / \mathrm{dl}$, with normochromic normocytic red blood cells and ESR $150 \mathrm{~mm} / 1 \mathrm{~h}$. White cell count was $11.84 \times 10^{9} / 1$ showing neutrophil leucocytosis and lymphopenia of $0.9 \times 10^{9} / 1$. Aspartate transaminase and lactate dehydrogenase were elevated respectively to $94 \mathrm{IU} / 1(4-30)$ and $1,258 \mathrm{IU} / 1$ $(225-550)$ and these remained persistently raised for 10 days. An abdominal ultrasound scan and bone marrow examination were essentially normal. 
After several blood cultures and urine cultures (which were negative), broad spectrum antibiotics were started.

On day 3 her blood pressure (BP) suddenly fell from $110 / 70 \mathrm{mmHg}$ to $80 / 40 \mathrm{mmHg}$, the blood urea and creatinine rose to $26.8 \mathrm{mmol} / 1$ (2.5-6.5) and $301 \mu \mathrm{mol} / 1(60-120)$, respectively, and the oxygen capacity fell to $7.3 \mathrm{ml} / \mathrm{dl}(18-22)$. Severe cardiac failure was diagnosed and she was treated with vigorous inotropic support and a blood transfusion. The urine output (previously normal) fell sharply to $20 \mathrm{ml} / \mathrm{h}$; the urine sediment was normal.

On day 4 a chest X-ray showed pulmonary oedema with a normal-sized heart, and echocardiography demonstrated severe global left ventricular (LV) dysfunction and normal valves.

On day 5 the BP fell further to $60 / 30 \mathrm{mmHg}$ and the chest X-ray showed a total 'white out' of the lungs. Left ventricular function was worse on echocardiography and the cardiac index, measured by Swan Ganz, was 1.2(3.0-4.5). Artificial ventilation and enoximone were commenced and imipenem with cilastatin replaced other broad spectrum antibiotics.

On the basis of immunological results which showed a positive anti-nuclear antibody (ANA 1:100, diffuse pattern), anti-Ro (SS-A) antibody and low $\mathrm{C} 3$ of $0.40(0.75-1.75 \mathrm{~g} / \mathrm{l})$ and $\mathrm{C} 4$ of 0.04 $(0.14-0.54 \mathrm{~g} / \mathrm{l})$, a diagnosis of lupus-like connective tissue disease was made on day 6 . Intravenous methylprednisolone $80 \mathrm{mg}$ daily was started immediately. Tests for antibodies to ds-DNA, SS-B (La), RNP, Jo-1, Centromere and neutrophil cytoplasmic antigen (ANCA) were negative. Rheumatoid factor was negative. The lupus anticoagulant test was positive but cardiolipin and myocardial antibody tests were negative. Serum immunoglobulins (IgG, IgM, IgA) and IgG subclass concentrations were within the normal range. The C-reactive protein was elevated at $109 \mathrm{mg} / \mathrm{l}$ $(<6 \mathrm{mg} / \mathrm{l})$. Her neutrophils showed normal phagocytosis and respiratory burst by the nitro blue tetrazolium test. Total $T$ lymphocytes, $T$ cell subsets $T 4$ and $T 8$, and $B$ lymphocytes were proportionately decreased, and compatible with the lymphopenia.

Within 48 hours she began improving rapidly from her near-terminal state, and the illness thereafter progressed steadily to full clinical, radiological and echocardiographic resolution.

She was discharged 25 days after hospital admission. She was closely monitored as an out-patient in the first few months after discharge, during which period her dose of prednisolone was reduced from $40 \mathrm{mg}$ per day to $7.5 \mathrm{mg}$ per day. Follow-up to date reveals that she leads a physically active life and is currently maintained on prednisolone $7.5 \mathrm{mg}$ daily. She remains normotensive with no evidence of cardiac or renal dysfunction, and maintains a normal haemoglobin level.

When her case notes from another hospital became available it was found that ANA positivity $(1: 1,600)$ and a few LE cells on buffy coat preparation were documented in 1982 when she presented with chest pains which were considered to be musculo-skeletal in origin. Normocytic, normochromic anaemia and high ESR were also found at that time, but the DNA antibody binding was negative, and on this basis SLE was 'excluded'. She did not receive any immuno-suppressive therapy, and as she was asymptomatic, she was discharged from follow-up in June 1984. Thereafter she had remained very well until this admission in April 1990. Her only complaint was of occasional upper limb symptoms suggestive of Raynaud's phenomenon.

Follow-up immunology continues to show evidence of moderate complement activation (low C3, $\mathrm{C} 4$ and $\mathrm{CH} 50$ with elevated C3d). The ANA remains positive as does anti-Ro antibody. Six months following her acute illness, ds-DNA (by RIA) became weakly positive for the first time. The anticardiolipin antibody (ACA) has now become marginally elevated and the lupus anticoagulant test remains positive. The lymphopenia has improved and the C-reactive protein is normal. Serological tests have been consistently negative for hepatitis A, B, C, Coxsackie B, atypical pneumonia organisms, salmonella, brucella, EpsteinBarr virus and cytomegalovirus.

\section{Discussion}

This patient's severe cardiac failure continued to deteriorate in spite of diuretics and intense inotropic support. Rapid resolution occurred only when steroid therapy was added to her management. In the absence of chest pain or electrocardiographic changes, myocardial infarction was most unlikely. Furthermore, the echocardiogram showed global myocardial dysfunction compatible with myocarditis, rather than myocardial infarction. Persistent fever, in the absence of a demonstrable infective cause, lymphopenia, high ESR, positive ANA and SS-A (Ro) with low C3 and C4 suggested a lupus-like connective tissue disease.

In this patient, the heart was the only organ shown to be primarily involved in this acute episode. She is unusual in her presentation with myocarditis with no clinical or echocardiographic evidence of pericarditis (the most common cardiac manifestation of SLE) or endocarditis. SLE myocarditis, however, is often silent in life, whereas it is detected in over $50 \%$ of SLE patients at postmortem examination. ${ }^{1}$ Despite the known myocardial involvement in SLE, the clinical occurrence of 
cardiac insufficiency due to lupus myocarditis per $s e$ is considered to be a rare occurrence. ${ }^{2}$ Histologically, lupus carditis is characterized by acute and chronic inflammation. Granular deposits of IgG in cardiac tissue have also been reported, suggesting immune complex aggregates. ${ }^{10}$

The persistently positive 'Ro' antibody in this patient raises an interesting question of possible myocardial damage from this antibody in adult patients. Hitherto, SS-A (Ro) antibody has been associated with congenital heart block and heart defects in neonates, born to 'Ro positive' mothers due to the transfer of maternal antibody across the placenta. ${ }^{11,12}$ The observation that these mothers did not manifest cardiac problems in spite of high concentrations of anti-Ro antibody was explained on the basis of the vulnerability of an immature fetal heart compared with that of an adult. The possible presence of maternal 'blocking' antibodies (of IgA or IgM class, which does not cross the placental barrier) may also be relevant, preventing the IgG antibody from damaging the mother's heart.

However, in a recent study of adult SLE, eight out of 36 patients with anti-Ro antibodies had conduction defects or myocarditis. In the anti-Ro negative group, only one out of 31 patients had a cardiac defect (right bundle branch block). ${ }^{13}$ These findings suggest that anti-Ro antibody may be associated with cardiac disorders in adults, as well as in neonates.

Recent reports also suggest an association between the lupus anticoagulant and valvular heart disease in SLE as well as non-SLE patients. ${ }^{14,15}$ In another report, extensive myocardial necrosis (as well as Libman-Sacks endocarditis) was found at autopsy in a young female with SLE and high anti-cardiolipin antibody. ${ }^{16}$ We have found no clinical or investigatory evidence of valve lesions or endocarditis in our patient although her lupus anticoagulant test remains positive.

SLE is a multi-system disease which can present to physicians in every speciality because of its multi-faceted symptomatology. It is important therefore to consider SLE or lupus-like disease even in acutely ill patients who do not have previously documented connective tissue disease. In patients presenting with cardiogenic shock of unknown aetiology a lupus-like syndrome should also be considered, because immuno-suppressives, and notably intra-venous steroids, may be the only therapy to affect the outcome radically. The absence of ds-DNA, or even ANA, does not completely rule out the possibility of SLE. ANA negativity is documented in patients with clinical SLE, and a proportion of these patients have been shown to be anti-Ro positive. ${ }^{9}$ Ideally, therefore, the diagnosis of SLE should not depend upon a single test, but on an 'immune profile' (including ANA, ds-DNA antibodies, anti-Ro and anti-La antibodies as well as complement components).

The results of immuno-serology should be evaluated in conjunction with the clinical picture, and a search for other antibodies made where appropriate. This approach could help in the early diagnosiso and treatment of lupus, 'lupus overlap' or 'lupus like' disorders.

\section{Acknowledgements}

We wish to thank Sheena Collins for preparation of the manuscript and Barbara Bolton for assistance with literature searches.

\section{References}

1. Ansari, A., Larson, P.H. \& Bates, H.D. Cardiovascular manifestations of systemic lupus erythematosus. Prog Cardiovasc Dis 1985, 27: 421-434.

2. Chang, R.W. Cardiac manifestations of systemic lupus erythematosus. Clin Rheum Dis 1981, 8: 197-206.

3. Fairfax, M.J., Osborn, T.G., Williams, G.A., Tsai, C.C. \& Moore, T.L. Endomyocardial biopsy in patients with systemic lupus erythematosus. $J$ Rheumatol 1988, 15: 593-596.

4. Been, M., Thomson, B.J., Smith, M.A. et al. Myocardial involvement in systemic lupus erythematosus detected by magnetic resonance imaging. Eur Heart J 1988, 9: 1250-1256.

5. Mackay, I.R., Autoimmunity in relation to lupus erythematosus. In: Wallace, D.J. (ed.) Dubois' Lupus Erythematosus, 3rd ed. Lea and Febiger, Philadelphia, 1987, pp. 44-52.

6. Dillon, C.F., Verrier Jones, J., Reichlin, M. et al. Antibody to Ro in a population of patients with systemic lupus erythematosus: distribution, clinical and serological associations. $J$ Rheumatol 1983, 10: 380-386.
7. Scopelitis, E., Biundo, J.J. \& Alspaugh, M.A. Anti SS-A antibody and other antinuclear antibodies in systemic lupus erythematosus. Arthritis Rheum 1980, 23: 287-293.

8. Hughes, G.R.V. Immunological tests in the rheumatic diseases. In: Hughes, G.R.V. (ed) Connective Tissue Diseases, 3rd ed. Blackwell Scientific Publications, Oxford, 1986, pp. 268-286.

9. Maddison, P.J., Provost, T.T. \& Reichlin, M. Serological findings in patients with 'ANA-negative' systemic lupus erythematosus. Medicine (Baltimore) 1986, 60: 87-94.

10. Bidani, A.K., Roberts, J.L., Schwartz, M.M. \& Lewis, E.J. Immunopathology of cardiac lesions in fatal systemic lupus erythematosus. Am J Med 1980, 69: 849-858.

11. Scott, J.S., Maddison, P.J., Taylor, P.V., Esscher, E., Scott, O. \& Skinner, R.P. Connective tissue disease, antibodies to ribo-nucleoprotein and congenital heart block. $N$ Engl J Med 1983, 309: 209-212.

12. Vetter, V.L. \& Rashkin, W.J. Congenital complete heart block and connective tissue disease. N Engl J Med 1983, 309: 236-238. 
13. Logar, D., Kveder, T., Rozman, B. \& Dobovisek, J. Possible association betwen anti-Ro antibodies and myocarditis or cardiac conduction defects in adults with systemic lupus erythematosus. Ann Rheum Dis 1990, 49: 627-629.

14. Ford, P.M., Ford, S.E. \& Lillicrap, D.P. Association of lupus anticoagulant with severe valvular heart disease in systemic lupus erythematosus. $J$ Rheumatol 1988, 15: 597-600.
15. Pope, J.M., Canny, C.L.B. \& Bell, D.A. Cerebral ischaemic events associated with endocarditis, retinal vascular disease and lupus anticoagulant. Am J Med 1991, 90: 299-309.

16. Brown, J.H. Doherty, C.C., Allen, D.C. \& Morton, P. Fatal cardiac failure due to myocardial microthrombi in systemic lupus erythematosus. Br Med J 1988, 296: 1505. 